\title{
Differential effects of mechanical strain on osteoclastogenesis and osteoclast-related gene expression in RAW264.7 cells
}

\author{
XIAO-YING XU ${ }^{1,2^{*}}$, CHUN GUO $^{3 *}$, YU-XIAN YAN $^{1}$, YONG GUO $^{1}$, RUI-XIN LI ${ }^{1}$, \\ MEI SONG ${ }^{1}$ and XI-ZHENG ZHANG ${ }^{1}$ \\ ${ }^{1}$ Institute of Medical Equipment, Academy of Military Medical Sciences, Tianjin 300161; ${ }^{2}$ Institute of Immunology, \\ School of Basic Medical Sciences, Southern Medical University, Guangzhou 510515, Guangdong; \\ ${ }^{3}$ Department of Orthopaedics, First Affiliated Hospital of Henan University, Kaifeng 475000, Henan, P.R. China
}

Received January 26, 2012; Accepted April 27, 2012

DOI: $10.3892 / \mathrm{mmr} .2012 .908$

\begin{abstract}
Mechanical strain plays a critical role in the formation, proliferation and maturation of bone cells. However, little is known about the direct effects of different magnitudes of mechanical strain on osteoclast differentiation. The aim of the present study was to investigate how the fusion and activation of osteoclasts can be regulated by mechanical strain magnitude using the RAW264.7 mouse monocyte/ macrophage cell line as an osteoclast precursor. Mechanical strain (substrate stretching) was applied via a 4-point bending system when RAW cells were treated with macrophage colonystimulating factor (M-CSF) and receptor activator of nuclear factor- $\kappa \mathrm{B}$ (RANK) ligand (RANKL) for an indicated period of time. The numbers of tartrate-resistant acid phosphatasepositive $\left(\mathrm{TRAP}^{+}\right)$and apoptotic cells were counted. The expression of TRAP, matrix metalloproteinase-9 (MMP-9), RANK, cathepsin K and carbonic anhydrase II (CAII) was measured by semi-quantitative RT-PCR, and immunocytochemistry staining for RANK was performed. We found that the number of nuclei per osteoclast derived from RAW cells decreased under low magnitude mechanical strain and increased under high magnitude strain within physiological load with an enhanced fusion of $\mathrm{TRAP}^{+}$osteoclasts, compared to the control with no mechanical strain. The expression of RANK mRNA was downregulated by low magnitude strain and beyond physiological load, while it was upregulated by high magnitude strain within physiological load, correlating with the increased expression of RANK examined by immunocytochemistry, suggesting the mechanical regula-
\end{abstract}

Correspondence to: Professor Xi-Zheng Zhang, Institute of Medical Equipment, Academy of Military Medical Science, 106 WanDong Road, Tianjin, Hebei 300161, P.R. China

E-mail: zxz56787@sohu.com

*Contributed equally

Key words: osteoclast, mechanical strain magnitude, differentiation, receptor activator of nuclear factor- $\mathrm{\kappa B}$ expression tion of RANK expression. There was also an increase in the expression of MMP-9 mRNA in the groups subjected to a mechanical strain of 2,000 and 2,500 $\mu \varepsilon$. No significant differences were detected in the expression of TRAP mRNA, cathepsin $\mathrm{K}$ and CAII under mechanical strain compared to the control under no strain $(0 \mu \varepsilon)$. These findings indicate that low-magnitude strain suppresses osteoclast fusion and activation, while high-magnitude strain within physiological load promotes osteoclast fusion and activation related to a mechanical magnitude-dependent response of RANK expression. These data, therefore, provide a deeper understanding of how different magnitudes of mechanical strains exert their effects on osteoclastogenesis.

\section{Introduction}

Bone is a dynamic tissue that constantly undergoes remodeling in which a coupled process of bone formation and resorption continues throughout life. This remodeling is necessary to maintain the structural integrity of the skeleton under conditions of changing mechanical forces. Over the past few decades, investigators have expounded mechanisms for the adaptive response of bone to mechanical stimuli, including the most well-known theory of mechanostat originally proposed by Frost $(1,2)$. It has been reported that disuse activates remodeling, but inhibits modeling, leading to bone loss, whereas overload inhibits remodeling and activates formation mode modeling, leading to bone gain. Furthermore, strain above 1,500 $\mu \varepsilon$ evokes bone increase (a positive adaptive response) and a strain below $100 \mu \varepsilon$ causes a loss of bone (a negative adaptive response), while a strain ranging from 100 to $1,500 \mu \varepsilon$ evokes no response. Bone tissue functionally adjusts its mass and architecture to mechanical stimuli, mainly depending on 2 cell types involved in remodeling, one of which is osteoblasts, engaged in bone formation, and the other is osteoclasts, mainly responsible for bone resorption. Excessive osteoclast bone resorption leads to bone loss resulting in skeletal pathologies, such as rheumatoid arthritis, periodontal disease, postmenopausal osteoporosis, implant osteolysis and tumor-associated bone loss (3). However, the understanding of the cellular mechanisms producing such a mechanically meaningful structure remains poor. 
The osteoclast is a macrophage polykaryon developed from the differentiation and fusion of hematopoietic precursors at or near the bone surface in response to the essential tumor necrosis factor (TNF) family-related signal molecule receptor activator of NF- $\mathrm{B}$ (RANK) ligand (RANKL) and macrophage colony-stimulating factor (M-CSF) $(4,5)$. RANKL directly engages a membrane receptor, RANK, on osteoclast precursors and mature osteoclasts to trigger multiple intracellular signaling cascades that stimulate osteoclast gene expression, development, function and survival (6). Mice deficient in RANKL or RANK have severe osteopetrosis due to osteoclastogenesis (7-10).

Bone tissue is sensitive to mechanical strain. In a previous study, in the establishment of a mechanobiology model of bone and functional adaptation, the ulna was subjected to peak strains of 2,000 and 3,000 $\mu \varepsilon$, suggesting a dose-dependent adaptation of bone to mechanical stimuli (11). However, to date, little is known about the mechanisms invovled in the dose-response relationship between mechanical stimuli and osteoclasts in vitro. Therefore, in the present study, the cells were stretched with cyclic predominantly uniaxial strain by substrate movement along a given axis in order to mimic the mechanical stimuli within or beyond physiological load. Strain magnitudes ranging from 0 to 5,000 $\mu \varepsilon$ were applied over a period of 3 days at a constant cycle number and frequency to explore the effect of mechanical strain magnitude on osteoclast fusion and activation.

\section{Materials and methods}

Cell culture. The RAW264.7 murine monocyte/macrophage cell line (obtained from the School of Basic Medicine of the Peking Union Medical College, Beijing, China) was used as an osteoclast precursor, that has been shown to differentiate into osteoclast-like cells in the presence of M-CSF and soluble RANKL (PeproTech Inc., Rocky Hill, NJ, USA) over a period of 4-5 days (12-14). The cells were cultured in $\alpha$-minimal essential medium ( $\alpha$-MEM; Gibco BRL, Rockville, MD, USA) supplemented with $10 \%$ (v/v) fetal bovine serum (FBS; Gibco), $1 \%$ (v/v) penicillin-streptomycin solution (Gibco), $10 \mathrm{mM}$ HEPES at $37^{\circ} \mathrm{C}$ in a humidified atmosphere of $95 \%$ air and $5 \% \mathrm{CO}_{2}$. For treatment with mechanical stretching, the cells were seeded onto $34.8-\mathrm{mm}$ cell culture plates at a density of $5 \times 10^{6}$ cells $/ \mathrm{cm}^{2}$. After overnight incubation, the cells were maintained in $\alpha$-MEM containing $10 \% \mathrm{FBS}, 1 \%$ (v/v) penicillin-streptomycin solution, $10 \mathrm{mM}$ HEPES, M-CSF (40 $\mathrm{ng} / \mathrm{ml})$ and RANKL (40 $\mathrm{ng} / \mathrm{ml})$ for 7 days. The medium was changed every 3 days.

Application of mechanical strain to cultured cells. A 4-point bending system (invented by the Institute of Medical Equipment, Academy of Military Medical Science, Tianjin, China), composed of a cell culture unit, loading unit and circuit controller, was used to apply uniaxial and homogeneous mechanical strain, as described previously (Fig. 1) (15). Strain magnitudes (substrate stretching) ranged from 1,000 to $5,000 \mu \varepsilon$, with a strain frequency fixed at $0.5 \mathrm{~Hz}$. After treatment with RANKL and M-CSF for 3 days, the cells were divided into 6 groups $(0,1,000,1,500,2,000,2,500$ and 5,000 $\mu \varepsilon)$ at random, and subjected to substrate stretching for 3 days for $1 \mathrm{~h}$
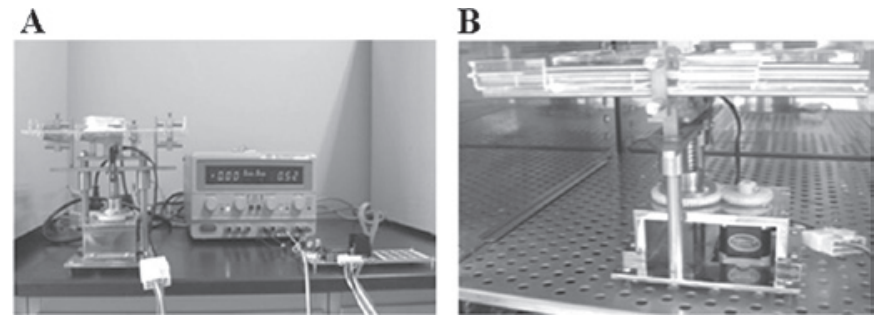

Figure 1. The principle of the mechanical strain (substrate streching) device composed of a cell culture unit, loading unit and circuit controller, supplying uniaxial and homogeneous mechanical strain. (A) Mechanical strain (substrate streching) system. (B) Cell culture unit and loading unit of the mechanical strain (substrate streching) device running in the sterile incubator.

per day, keeping the original culture condition unchanged (16). After 3 days of substrate stretching, the cells were harvested for the following experiments. The control culture was grown under the same condition without mechanical strain.

Morphological observation and tartrate-resistant acid phosphatase (TRAP) staining. After substrate stretching, the cells from each group were washed twice with phosphate-buffered saline (PBS) and stained with TRAP, using a leukocyte acid phosphatase kit (Institute of Hematology and Blood Diseases Hospital Chinese Academy of Medical Sciences, Tianjin, China). The $\mathrm{TRAP}^{+}$multinucleated cells ( $\geq 5$ nuclei) in 3 representative fields were manually enumerated as osteoclasts under a microscope.

Immunocytochemistry. The cells were washed 3 times with PBS after substrate stretching and then fixed in $4 \%(\mathrm{v} / \mathrm{v})$ paraformaldehyde. Permeabilization was performed with $0.2 \%$ (v/v) Triton X-100 (Sigma Aldrich Chemical Co., St. Louis, MO, USA), then the cells were incubated in $3 \% \mathrm{H}_{2} \mathrm{O}_{2}$ to quench the endogenous peroxidase activity. After washing with PBS, the samples were incubated with anti-RANK polyclonal antibody (Santa Cruz Biotechnology, Santa Cruz, CA, USA; working dilution, 1:200) at $4^{\circ} \mathrm{C}$ overnight using the peroxidase-conjugated mouse $\mathrm{IgG}$ SABC kit (Wuhan Boster Biological Technology, Ltd., Wuhan, China). After the peroxidase detection, cells were washed with PBS 4 times using the DAB Chromogenic kit (Wuhan Boster Biological Technology, Ltd.). Seal slide with balsam neutral and average optical density of RANK was calculated. The control samples were incubated in the same way with $0.01 \mathrm{M}$ PBS alone, instead of primary antibody.

Apoptosis of osteoclasts. The cells from each group were washed twice with PBS and then fixed in $4 \%(\mathrm{v} / \mathrm{v})$ paraformaldehyde. The fixed cells were stained with $1 \mu \mathrm{g} / \mathrm{ml}$ DAPI for $20 \mathrm{~min}$ at room temperature. After washing with PBS, the nuclear morphology of the cells was observed by fluorescence microscopy. Triplicate samples were prepared for each group and cells with condensed nuclei were counted in a selected field of each sample.

$R T-P C R$. The cells from each group were harvested as described above followed by RNA extraction using TRIzol reagent (Invitrogen) according to the manufacturer's instructions. cDNA was synthesized with $3 \mu \mathrm{g}$ of total RNA, oligo(dT) primer and 
Table I. Nucleotide sequences of the used primers.

\begin{tabular}{|c|c|c|c|c|}
\hline Gene & $\begin{array}{l}\text { GeneBank }^{\mathrm{TM}} \\
\text { accession no. }\end{array}$ & $\begin{array}{l}\text { Product size } \\
\quad(\mathrm{bp})\end{array}$ & $\begin{array}{l}\text { Temperature cycling } \\
\text { (cycle no.) }\end{array}$ & $\begin{array}{l}\text { Forward }(\mathrm{F}) \text { and reverse }(\mathrm{R}) \text { primer sequences } \\
\qquad\left(5^{\prime}-3^{\prime}\right)\end{array}$ \\
\hline TRAP & NM_007388 & 465 & $\begin{array}{l}94^{\circ} \mathrm{C}, 25 \mathrm{sec} ; 57^{\circ} \mathrm{C}, 30 \mathrm{sec} \\
68^{\circ} \mathrm{C}, 35 \mathrm{sec}(32)\end{array}$ & $\begin{array}{l}\text { ACACAGTGATGCTGTGTGGCAACTC }(\mathrm{F}) \\
\text { CCAGAGGCTTCCACATATATGATGG }(\mathrm{R})\end{array}$ \\
\hline MMP-9 & NM_013599 & 354 & $\begin{array}{l}94^{\circ} \mathrm{C}, 25 \mathrm{sec} ; 64^{\circ} \mathrm{C}, 30 \mathrm{sec} \\
68^{\circ} \mathrm{C}, 35 \mathrm{sec}(32)\end{array}$ & $\begin{array}{l}\text { CGAGTGGACGCGACCGTAGTTGG }(\mathrm{F}) \\
\text { CAGGCTTAGAGCCACGACCATACAG }(\mathrm{R})\end{array}$ \\
\hline RANK & NM_009399 & 351 & $\begin{array}{l}94^{\circ} \mathrm{C}, 25 \mathrm{sec} ; 57^{\circ} \mathrm{C}, 30 \mathrm{sec} \\
68^{\circ} \mathrm{C}, 35 \mathrm{sec}(32)\end{array}$ & $\begin{array}{l}\text { ACCTCCAGTCAGCAAGAAGT (F) } \\
\text { TCACAGCCCTCAGAATCCAC (R) }\end{array}$ \\
\hline CAII & NM_009801 & 407 & $\begin{array}{l}94^{\circ} \mathrm{C}, 25 \mathrm{sec} ; 54^{\circ} \mathrm{C}, 30 \mathrm{sec} \\
68^{\circ} \mathrm{C}, 35 \mathrm{sec}(32)\end{array}$ & $\begin{array}{l}\text { CTTCAGGACAATGCAGTGC (F) } \\
\text { ATCCAGGTCACACATTCCAGC (R) }\end{array}$ \\
\hline Cath K & NM_007802 & 364 & $\begin{array}{l}94^{\circ} \mathrm{C}, 25 \mathrm{sec} ; 56^{\circ} \mathrm{C}, 30 \mathrm{sec} \\
68^{\circ} \mathrm{C}, 35 \mathrm{sec}(32)\end{array}$ & $\begin{array}{l}\text { CTGAAGATGCTTTCCCATATGTGGG (F) } \\
\text { GCAGGCGTTGTTCTTATTCCGAG }(\mathrm{R})\end{array}$ \\
\hline$\beta$-actin & NM_007393 & 306 & $\begin{array}{l}94^{\circ} \mathrm{C}, 25 \mathrm{sec} ; 55^{\circ} \mathrm{C}, 30 \mathrm{sec} \\
68^{\circ} \mathrm{C}, 35 \mathrm{sec}(32)\end{array}$ & $\begin{array}{l}\text { GAAGAGCTATGAGCTGCCTG (F) } \\
\text { CACAGAGTACTTGCGCTCAG (R) }\end{array}$ \\
\hline
\end{tabular}

TRAP, tartrate-resistant acid phosphatase; MMP-9, matrix metalloproteinase-9; RANK, receptor activator of nuclear factor- $\mathrm{kB}$; CAII, carbonic anhydrase II; Cath K, cathepsin K.

the TIANScript RT kit (Tiangen Biotech, Beijing, China). The following primers were used: RANK, TRAP, matrix metalloproteinase-9 (MMP-9), cathepsin K and carbonic anhydrase II (CAII). PCRs were conducted by initial denaturation at $94^{\circ} \mathrm{C}$ for $3 \mathrm{~min} 30 \mathrm{sec}$, with $1 \mu \mathrm{l}$ of reverse transcriptase product added. The sequences of the used primers are shown in Table I. PCR products were separated by $1.5 \%$ agarose gel electrophoresis, stained with ethidium bromide, photographed using Gel-Doc (Bio-Rad) and quantified by density determination using Quantity One image analysis software (Bio-Rad). The results were normalized to $\beta$-actin signals determined in parallel for each sample, and the data expressed as a ratio of the target gene to $\beta$-actin. All amplicons were of the expected size (Table I), and products were directly sequenced to confirm identities by comparison with sequences published using computation performed at NCBI and the BLAST network service.

Statistical analysis. Data are presented as the means $\pm \mathrm{SE}$, typically from 2 to 3 independent trials, each with 3 replicates. Statistical comparisons between the treatment groups were performed using one-way analysis of variance. For simultaneous comparisons between multiple treatments, significant differences were determined using Bonferroni's post hoc analysis of variance test; $\mathrm{p}<0.05$ denoted a statistically significant difference.

\section{Results}

Osteoclasts change morphologically and the number of TRAP-positive multinucleated osteoclasts vary depending on the magnitude of mechanical strain. Osteoclasts in culture with M-CSF and RANKL were observed with representative typical multinuclei. After substrate stretching, the number of $\mathrm{TRAP}^{+}$multinucleated osteoclasts significantly decreased in the groups subjected to a strain of 1,000 and 1,500 $\mu \varepsilon$ as compared to the control, whereas there was no significant difference in the groups subjected to a strain of 2,000 and 2,500 $\mu \varepsilon$ compared to the control (Figs. 2A and B, and 3A).

Expression of RANK increases under high mechanical strain within physiological load. RANK is the sole signaling receptor for RANKL in the process of inducing the development and activation of osteoclasts. In immunocy tochemistry staining for RANK, the groups subjected to a strain of 2,000 and $2,500 \mu \varepsilon$ showed stronger positive staining than the control after substrate stretching (Fig. 3B).

Osteoclast apoptosis is induced by substrate stretching of low magnitude. The number of apoptotic osteoclasts increased with the mechanical strain of 1,000 and 1,500 $\mu \varepsilon$ compared to the control, whereas no significant stimulation was observed in the groups subjected to a strain of 2,000, 2,500 and 5,000 $\mu \varepsilon$ (Fig. 4A and B).

Expression of RANK and MMP-9 genes differs depending on different magnitudes of mechanical strain. The expression of RANK mRNA increased in the groups subjected to a strain of 2,000 and 2,500 $\mu \varepsilon$, while it decreased in the groups subjected to a strain of $1,000,1,500$ and $5,000 \mu \varepsilon$. The expression of MMP9 mRNA increased in the groups subjected to a strain of 2,000 and 2,500 $\mu \varepsilon$, while there were no significant differences in the groups subjected to a strain of 1,000, 1,500 and $5,000 \mu \varepsilon$. There were no significant differences in the expression of TRAP, cathepsin K and CAII mRNA under mechanical strain compared to the control (Fig. 5).

\section{Discussion}

Since the pioneering work of Frost, it has become generally accepted that bone tissue maintains its structure throughout 


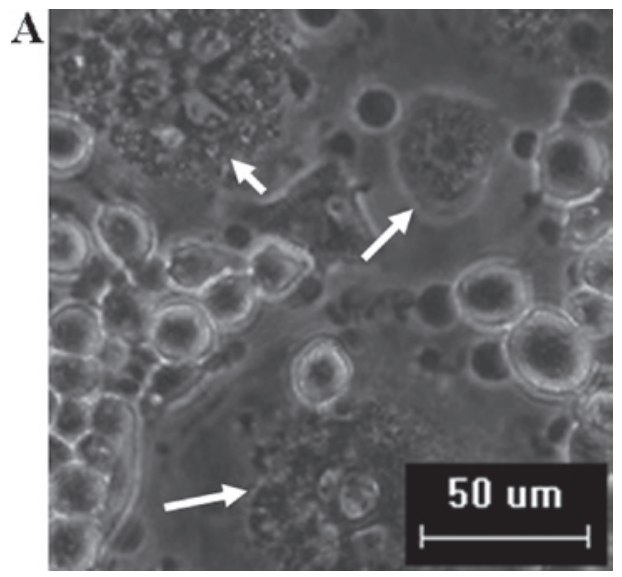

B

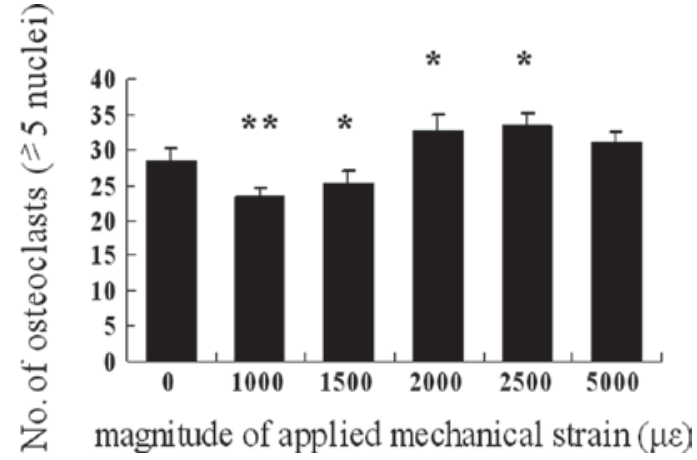

Figure 2. RAW264.7 cells $\left(5 \times 10^{6} / \mathrm{cm}^{2}\right)$ were cultured in 34.8-mm tissue culture plates with macrophage colony-stimulating factor (M-CSF) and receptor activator of nuclear factor- $\mathrm{kB}$ ligand (RANKL). Mechanical strain of different magnitudes was applied for $1 \mathrm{~h} / \mathrm{day}$ for 3 days and at day 4, but not to the control, keeping the culture condition unchanged. (A) Typical multinucleated cells without substate streching. (B) The number of neclei/cell varied depending on the magnitude of mechanical strain, osteoclasts with $\geq 5$ nuclei were counted at day 7. Results are presented as the means $\pm \mathrm{SD}(\mathrm{n}=6)$. ${ }^{*} \mathrm{p}<0.05,{ }^{* *} \mathrm{p}<0.01$.

A

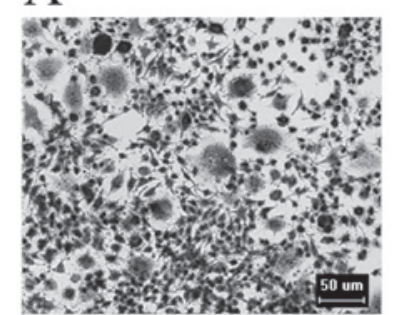

$0 \mu \varepsilon(\mathrm{CTRL})$

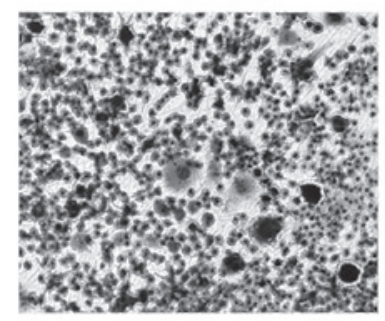

$1500 \mu \varepsilon$

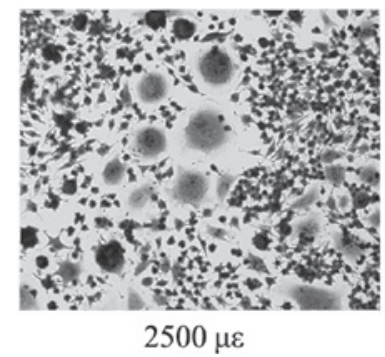

B

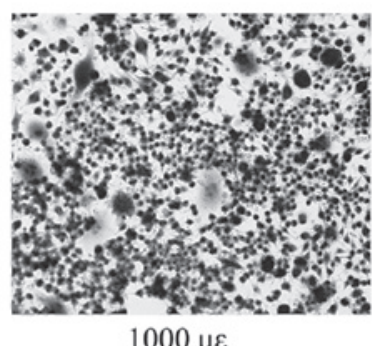
$1000 \mu \varepsilon$

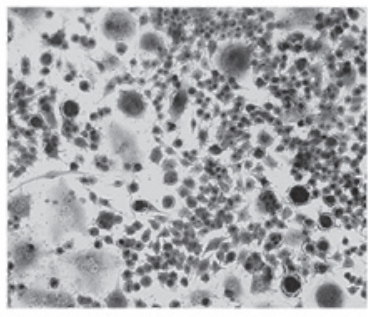

$2000 \mu \varepsilon$

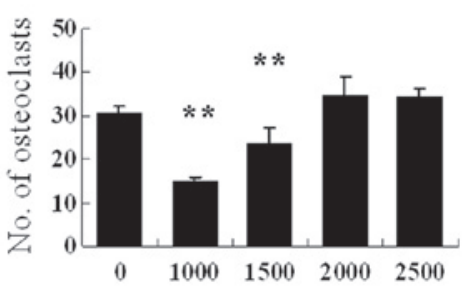

magnitude of mechanical strain $(\mu \varepsilon)$

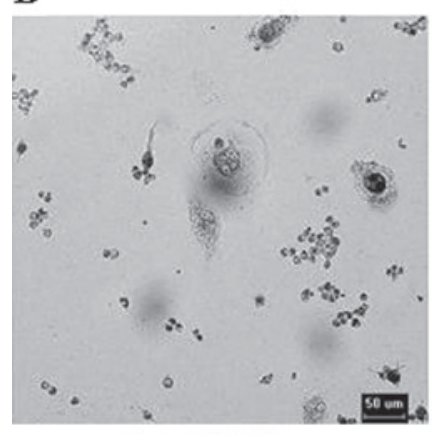

$0 \mu \varepsilon$ (CTRL)
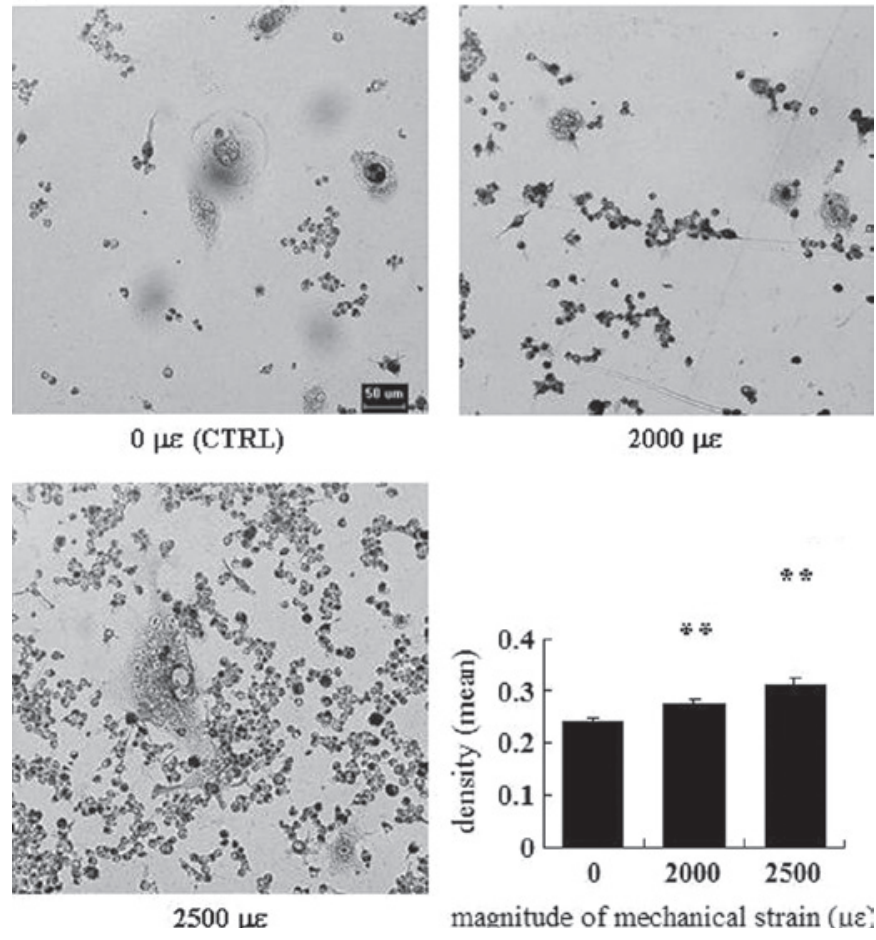

$2000 \mu \varepsilon$

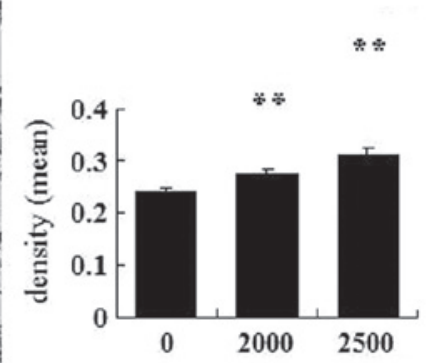

magnitude of mechanical strain (uع)

Figure 3. The number of tartrate-resistant acid phosphatase (TRAP)-positive multinucleated osteoclasts and receptor activator of nuclear factor- $\mathrm{kB}$ (RANK) expression varied depending on the magnitude of mechanical strain. RAW cells $\left(5 \times 10^{6} / \mathrm{cm}^{2}\right)$ were cultured in $34.8-\mathrm{mm}$ tissue culture plates for 3 days, followed by the cells that were subjected to substrate mechanical stretching at different magnitudes for another 3 days, keeping the culture condition unchanged. After 6 days in culture, immunocytochemistry was performed. (A) TRAP ${ }^{+}$multinucleated cells were counted in 3 representative fields. (B) Optical density (mean) of RANK was calculated. Results are presented as the means $\pm \mathrm{SD}(\mathrm{n}=6) .{ }^{* *} \mathrm{p}<0.01$.

life by the coupled activities of bone-forming osteoblasts and bone-resorbing osteoclasts. The skeleton is able to continually adapt to the mechanical environment by adding new bone to withstand increased amounts of loading, and by removing bone in response to unloading or disuse. Furthermore, most adult skeletal diseases are due to excess osteoclastic activity. Studies have shown that mechanical strain inhibits osteoclast differentiation indirectly by osteoblasts and stromal cells $(17,18)$. Other reports have shown that compressive mechanical stress promoted osteoclast formation through RANKL expression in 


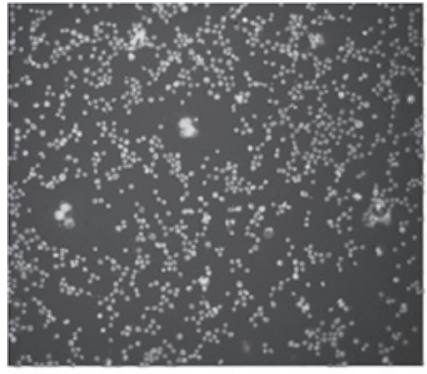

$0 \mu \varepsilon$ (CTRL)

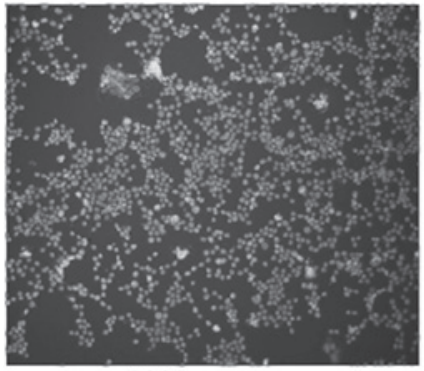

$2000 \mu \varepsilon$

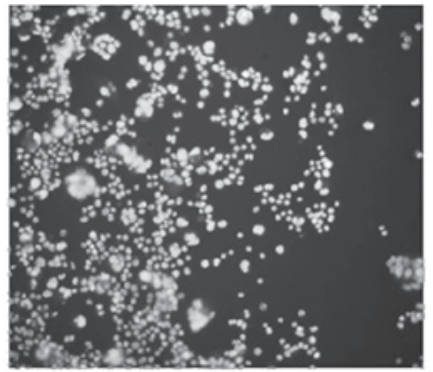

$1000 \mu \varepsilon$

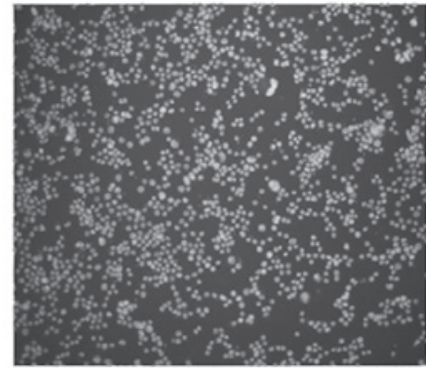

$2500 \mu \varepsilon$

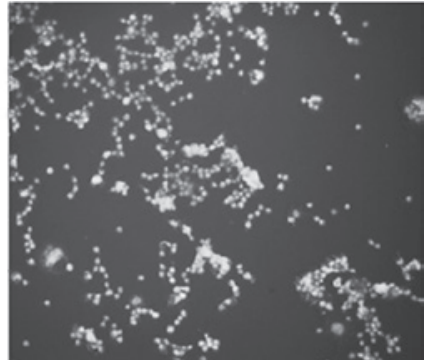

$1500 \mu \varepsilon$

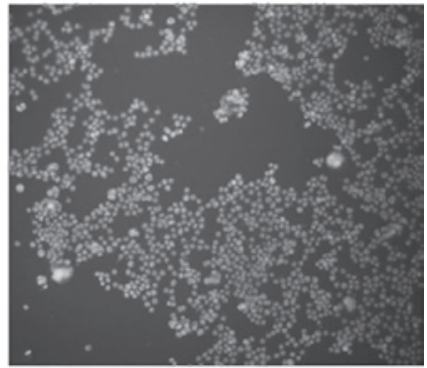

$5000 \mu \varepsilon$
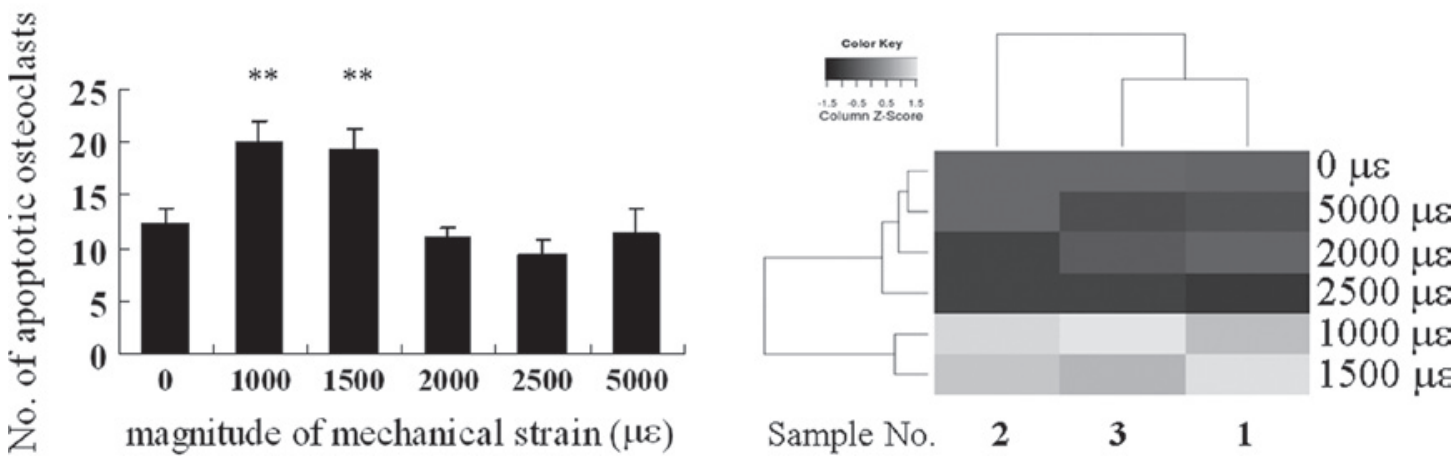

Figure 4. The number of apoptotic osteoclasts varied depending on the magnitude of mechanical strain. After 7 days in culture with different magnitudes of mechanical strain, apoptotic cells were counted with DAPI staining in a representative field of each sample. Heatmap shows the relationships between data categories and diverse trends of cell survival between the groups of different mechanical strain magnitudes. Results are presented as the means \pm SD ( $=6$ ). ** $\mathrm{p}<0.01$. CTRL, control.

\section{$\begin{array}{llllll}0 & 1000 & 1500 & 2000 & 2500 & 5000\end{array}(\mu \varepsilon)$}
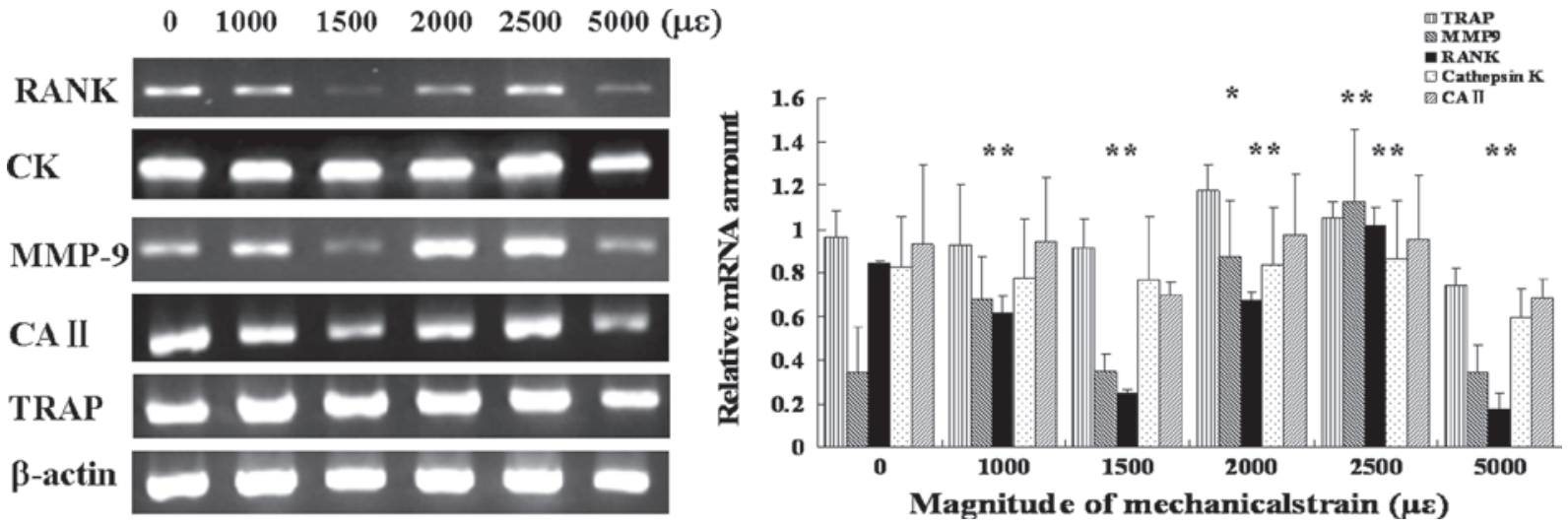

Figure 5. Mechanical strain was related to the expression of osteoclast differentiation genes. RAW cells $\left(5 \times 10^{6} / \mathrm{cm}^{2}\right)$ were cultured in 34.8 -mm tissue culture plates with receptor activator of nuclear factor- $\mathrm{kB}$ ligand (RANKL) and macrophage colony-stimulating factor (M-CSF), and subjected to different magnitudes of mechanical strain (substrate stretching) at day 4. After 3 days of culture with or without mechanical stimulation, total RNA was extracted, and RT-PCR analysis was performed using the primers shown in Table I. The mRNA amount of the target gene/ $\beta$-actin was calculated. Results represent the means $\pm \mathrm{SD}(\mathrm{n}=6)$. ${ }^{\mathrm{p}}<0.05$, ${ }^{* *} \mathrm{p}<0.01$.

synovial cells (19). Ceratin studies have shown that mechanical strain also directly suppresses osteoclast differentiation $(13,20,21)$; others have proven that mechanical stimuli enhance osteoclast differentiation and activities (22-24). However, little is known about the direct effects of different magnitudes of mechanical strain on osteoclast differentiation. 
The amount of nuclei per osteoclast decreased significantly with a mechanical strain of 1,000 and 1,500 $\mu \varepsilon$, while the number of osteoclasts with 5 or more nuclei increased when the loading magnitude was tuned to 2,000 and 2,500 $\mu \mathrm{\varepsilon}$ compared to the control with no strain $(0 \mu \varepsilon)$ (Fig. 2). When TRAP staining was performed, the number of osteoclasts was found to be downregulated by low mechanical strain (Fig. 3A). It is well known that RANK signaling is essential for osteoclast differentiation, activation and survival. In immunocytochemistry staining of osteoclasts for RANK, the groups subjected to a strain of 2,000 and $2,500 \mu \varepsilon$ showed stronger positive staining than the control after 3 days of substrate stretching (Fig. 3B). These findings indicate that a mechanical strain of low magnitude within physiological load inhibits osteoclast differentiation, but promotes the fusion of mononuclear osteoclasts related to high magnitude strain. A strain of 5,000 $\mu \varepsilon$ regarded as high magnitude beyond physiological load had little effect (data not shown).

In RT-PCR analysis (Fig. 5), RANK mRNA expression decreased with the mechanical strain of 1,000, 1,500 and 5,000 $\mu \varepsilon$, while both RANK and MMP-9 increased with the mechanical strain of 2,000 and 2,500 $\mu \varepsilon$ compared to the control. RANK mediated the ability of precursor cells to undergo differentiation. The selective inhibition of RANK with RANK:Fc or RANK receptor inhibitor has been shown to block osteoclast maturation and function in vivo or in vitro (25-27). MMP-9 has been proven to be indispensable for the migration of osteoclasts through collagen, both in the periosteum and developing marrow cavity of primitive long bones $(28,29)$. MMP-9 antisense oligonucleotides exert an inhibitory effect on osteoclastic bone resorption by suppressing cell migration (30). Bone resorption is specifically reduced by the chemical inhibition of MMP-9 $(31,32)$. The results of this study suggest the involvement of both RANK and MMP-9 expression depending on the mechanical strain magnitude, thus indicating that low-magnitude strain suppresses osteoclast differentiation, while high-magnitude strain within physiological load stimulates osteoclast fusion and activation.

We examined the apoptotic osteoclasts under mechanical strain. Compared to the control, apoptotic osteoclasts increased with the mechanical strain of 1,000 and 1,500 $\mu \varepsilon$, whereas there was no significant stimulation was observed with a strain of 2,000, 2,500 and 5,000 $\mu \varepsilon$ (Fig. 4), suggesting that apoptosis occurs when a mechanical strain of low magnitude is applied. A heatmap produced by the heatmap function from $\mathrm{R}$ intuitively indicated the diverse trends of cell survival between the groups of different mechanical strain magnitudes as well.

Currently, mechanical exercise appears to be a concern for clinicians as a co-ordinated treatment. Little is known about how different magnitudes of mechanical strain exert an effect on the differentiation and fusion of osteoclasts. The data from our study provide a further understanding of the diverse regulation by different magnitudes of mechanical strain, leading to the development of therapeutics optimized for diseases related to bone loss. We found that mechanical strain turned out to be inhibitory towards RAW264.7 cell differentiation at a low magnitude, but stimulatory at a high magnitude within physiological load. The osteoclasts morphologically changed depending on the different magnitudes mechanical strain. The expression of RANK and related genes also changed depending on different magnitutes of strain. TRAP is often used as one of the macrophage/osteoclast lineage markers $(33,34)$. However, the results of the present study on mRNA expression are in disagreement with those from the study of Fujisaki et al, who observed that the expression of CAII and cathepsin $\mathrm{K}$ induced by RANKL was increased according to the maturity and differentiation of the RAW264.7 cells (35). No significant differences were observed in the expression of TRAP, cathepsin K and CAII mRNA under mechanical strain compared to the control. Therefore, RANKL/osteoprotegerindependent signal transduction pathways are possibly more active during late differentiation than TRAP-dependent pathways. However, further study of other co-stimulators and/ or mechanisms unknown during various stages of osteoclast development differentially regulated by mechanical strain is warranted.

\section{Acknowledgements}

The authors are grateful to their colleagues at the Institute of Medical Equipment, Academy of Military Medical Science, for their tremendous support. The study was supported by the National Natural Science Foundation Key Program of China (no. 10832012).

\section{References}

1. Frost HM: Bone Remodeling Dynamics. Thomas CC (ed). Springfield, IL, 1963.

2. Frost HM: Bone 'mass' and the 'mechanostat': a proposal. Anat Rec 219: 1-9, 1987.

3. Teitelbaum SL: Osteoclasts: what do they do and how do they do it? Am J Pathol 170: 427-435, 2007.

4. Kodama H, Nose M, Niida S and Yamasaki A: Essential role of macrophage colony-stimulating factor in the osteoclast differentiation supported by stromal cells. J Exp Med 173: 1291-1294, 1991.

5. Yasuda H, Shima N, Nakagawa N, et al: Identity of osteoclastogenesis inhibitory factor (OCIF) and osteoprotegerin (OPG): a mechanism by which OPG/OCIF inhibits osteoclastogenesis in vitro. Endocrinology 139: 1329-1337, 1998.

6. Mochizuki A, Takami M, Kawawa T, et al: Identification and characterization of the precursors committed to osteoclasts induced by TNF-related activation-induced cytokine/receptor activator of NF-kappa B ligand. J Immunol 177: 4360-4368, 2006.

7. Kong YY, Yoshida H, Sarosi I, et al: OPGL is a key regulator of osteoclastogenesis, lymphocyte development and lymph-node organogenesis. Nature 397: 315-323, 1999.

8. Kim N, Odgren PR, Kim DK, Marks SC Jr and Choi Y: Diverse roles of the tumor necrosis factor family member TRANCE in skeletal physiology revealed by TRANCE deficiency and partial rescue by a lymphocyte-expressed TRANCE transgene. Proc Nat Acad Sci USA 97: 10905-10910, 2000.

9. Dougall WC, Glaccum M, Charrier K, et al: RANK is essential for osteoclast and lymph node development. Genes Dev 13: 2412-2424, 1999.

10. Li J, Sarosi I, Yan XQ, et al: RANK is the intrinsic hematopoietic cell surface receptor that controls osteoclastogenesis and regulation of bone mass and calcium metabolism. Proc Nat Acad Sci USA 97: 1566-1571, 2000.

11. Chen XY, Zhang XZ, Guo Y, Li RX, Lin JJ and Wei Y: The establishment of a mechanobiology model of bone and functional adaptation in response to mechanical loading. Clin Biomech (Bristol, Avon) 23 (Suppl 1): 88-95, 2008.

12. Suda T, Takahashi N, Udagawa N, Jimi E, Gillespie MT and Martin TJ: Modulation of osteoclast differentiation and function by the new members of the tumor necrosis factor receptor and ligand families. Endoc Rev 20: 345-357, 1999.

13. Suzuki N, Yoshimura Y, Deyama Y, Suzuki K and Kitagawa Y: Mechanical stress directly suppresses osteoclast differentiation in RAW264.7 cells. Int J Mol Med 21: 291-296, 2008. 
14. Takahashi N, Udagawa N, Tanaka S and Suda T: Generating murine osteoclasts from bone marrow. Methods Mol Med 80: 129-144, 2003.

15. Tang LL, Wang YL, Pan J and Cai SX: The effect of step-wise increased stretching on rat calvarial osteoblast collagen production. J Biomech 37: 157-161, 2004.

16. Shibata K, Yoshimura Y, Kikuiri T, et al: Effect of the release from mechanical stress on osteoclastogenesis in RAW264.7 cells. Int J Mol Med 28: 73-79, 2011.

17. Kreja L, Liedert A, Hasni S, Claes L and Ignatius A: Mechanical regulation of osteoclastic genes in human osteoblasts. Biochem Biophys Res Commun 368: 582-587, 2008.

18. Rubin J, Murphy T, Nanes MS and Fan X: Mechanical strain inhibits expression of osteoclast differentiation factor by murine stromal cells. Am J Physiol 278: C1126-1132, 2000.

19. Ichimiya H, Takahashi T, Ariyoshi W, Takano H, Matayoshi T and Nishihara T: Compressive mechanical stress promotes osteoclast formation through RANKL expression on synovial cells. Oral Surg Oral Med Oral Pathol Oral Radiol Endod 103 334-341, 2007.

20. Rubin J, Fan X, Biskobing DM, Taylor WR and Rubin CT: Osteoclastogenesis is repressed by mechanical strain in an in vitro model. J Orthop Res 17: 639-645, 1999.

21. Burger EH, Klein-Nulend J and Smit TH: Strain-derived canalicular fluid flow regulates osteoclast activity in a remodelling osteon - a proposal. J Biomech 36: 1453-1459, 2003.

22. McAllister TN, Du T and Frangos JA: Fluid shear stress stimulates prostaglandin and nitric oxide release in bone marrow-derived preosteoclast-like cells. Biochem Biophys Res Commun 270: 643-648, 2000.

23. Kurata K, Uemura T, Nemoto A, et al: Mechanical strain effect on bone-resorbing activity and messenger RNA expressions of marker enzymes in isolated osteoclast culture. J Bone Miner Res 16: 722-730, 2001.

24. Zhang Q, Liang X, Zhu B, et al: Effects of fluid shear stress on mRNA expression of carbonic anhydrase II in polarized rat osteoclasts. Cell Biol Int 30: 714-720, 2006.

25. Childs LM, Paschalis EP, Xing L, et al: In vivo RANK signaling blockade using the receptor activator of NF- $\kappa \mathrm{B}: \mathrm{Fc}$ effectively prevents and ameliorates wear debris-induced osteolysis via osteoclast depletion without inhibiting osteogenesis. J Bone Miner Res 17: 192-199, 2002.
26. Feeley BT, Liu NQ, Conduah AH, et al: Mixed metastatic lung cancer lesions in bone are inhibited by noggin overexpression and Rank:Fc administration. J Bone Miner Res 21: 1571-1580, 2006.

27. Kim H, Choi HK, Shin JH, et al: Selective inhibition of RANK blocks osteoclast maturation and function and prevents bone loss in mice. J Clin Invest 119: 813-825, 2009.

28. Blavier L and Delaisse JM: Matrix metalloproteinases are obligatory for the migration of preosteoclasts to the developing marrow cavity of primitive long bones. J Cell Sci 108: 3649-3659, 1995.

29. Sato T, Foged NT and Delaissé JM: The migration of purified osteoclasts through collagen is inhibited by matrix metalloproteinase inhibitors. J Bone Miner Res 13: 59-66, 1998.

30. Ishibashi O, Niwa S, Kadoyama K and Inui T: MMP-9 antisense oligodeoxynucleotide exerts an inhibitory effect on osteoclastic bone resorption by suppressing cell migration. Life Sci 79: 1657-1660, 2006.

31. Hill PA, Murphy G, Docherty AJ, et al: The effects of selective inhibitors of matrix metalloproteinases (MMPs) on bone resorption and the identification of MMPs and TIMP-1 in isolated osteoclasts. J Cell Sci 107 (Pt 11): 3055-3064, 1994.

32. Spessotto P, Rossi FM, Degan M, et al: Hyaluronan-CD44 interaction hampers migration of osteoclast-like cells by downregulating MMP-9. J Cell Biol 158: 1133-1144, 2002.

33. Alatalo SL, Halleen JM, Hentunen TA, Monkkonen J and Vaananen HK: Rapid screening method for osteoclast differentiation in vitro that measures tartrate-resistant acid phosphatase $5 \mathrm{~b}$ activity secreted into the culture medium. Clin Chem 46: 1751-1754, 2000.

34. Rissanen JP, Suominen MI, Peng Z and Halleen JM: Secreted tartrate-resistant acid phosphatase $5 \mathrm{~b}$ is a Marker of osteoclast number in human osteoclast cultures and the rat ovariectomy model. Calcif Tissue Int 82: 108-115, 2008.

35. Fujisaki K, Tanabe N, Suzuki N, et al: Receptor activator of NF-kappaB ligand induces the expression of carbonic anhydrase II, cathepsin K, and matrix metalloproteinase-9 in osteoclast precursor RAW264.7 cells. Life Sci 80: 1311-1318, 2007. 